A - preparing concepts

$\mathrm{B}$ - formulating methods

$\mathrm{C}$ - conducting research

$\mathrm{D}$ - processing results

E - interpretation and conclusions

$\mathrm{F}$ - editing the final version

\section{Changes in balance and fall risk in female members of the Third Age University aged 60 and older}

\author{
Grzegorz Bednarczuk*A-F (D) \\ Faculty of Rehabilitation, Józef Piłsudski University of Physical Education in \\ Warsaw, Poland
}

*Correspondence: Grzegorz Bednarczuk; Józef Piłsudski University of Physical Education in Warsaw, Marymoncka 34, 00-968 Warsaw, Poland; email: bednarczuk. awf@gmail.com

\begin{abstract}
Introduction: Ageing processes are accompanied by degenerative changes within all functional and anatomical systems. These changes affect postural stability. This study sought to compare balance and fall risk indexes taking into account the age of the participants.

Material and methods: The study included female members $(n=59)$ of the University of the Third Age (U3A) set up at the University of Physical Education in Warsaw. The participants were divided into five age groups: 1 (60-64 years), 2 (65-69), 3 (70-74), 4 (75-79) and 5 (>80). Biodex Balance System was applied in the study. The overall stability index (OSI), the anteroposterior stability index (APSI), the mediolateral stability index (MLSI) and the fall risk test were used in the analysis. The participants performed tests that involved standing on both feet with eyes open and closed on a stable surface as well as standing with eyes open on an unstable surface. ANOVA was used to assess balance with regard to age. U Mann-Whitney test was employed to compare groups in terms of balance and the fall risk $(\mathrm{p}<0.05)$.

Results: The oldest group demonstrated the worst balance performance with eyes open: OSI $-0.70 \pm 0.47$; APSI $0.49 \pm 0.30$; MLSI $-0.37 \pm 0.43$. The best values of balance performance were manifested by the subjects aged $65-69$ : OSI $-0.36 \pm 0.13$; APSI $-0.25 \pm 0.08$; MLSI $-0.18 \pm 0.11$. Compared to eyes-open conditions, the tests performed with eyes closed revealed the smallest differences between the groups in OSI. The lowest fall risk was noted in groups 1 and 2. The highest fall risk index was found in group 4.

Conclusions: The findings of the study show that older adults depend on their vision when keeping balance. Physical activity exerts a positive influence on their balance and reduces the risk of falling. However, balance performance deteriorates and the fall risk increases with ageing.
\end{abstract}

Keywords: falls, balance, postural stability

\section{Introduction}

Ageing processes are accompanied by degenerative changes within all functional and anatomical systems. They are caused by tissue ageing as well as inhibiting biological processes, metabolism and regenerative processes [1-3]. Ageing leads to a decrease in muscle strength, volume and mass as well as a reduction in muscle fibres and changes within motor units [4]. All this results in a gradual impairment of motor and postural 
functions that affects postural stability directly [1]. Proper postural stability requires constant physiological regulation of the complex set of receptors that include the vestibular and visual systems, proprioceptors, haptic and pressure receptors. Impulses that reach such effectors as trunk, limb and extraocular muscles produce involuntary reactions that help to control body posture [5]. Keeping balance is possible owing to a continuous active postural regulation using the balance system that counterbalances destabilising factors in a static and dynamic manner through the activation of proper muscle groups [1]. Balance is the ability to maintain the gravity centre of the body in the base of the support [6]. It is the state in which forces that influence the body and their moments become similar, and their certain level is needed when performing activities of daily living and taking up physical activity [7].

In older adults, balance disorders may be caused by dysfunctions of any element responsible for its control, as it deteriorates with ageing. These processes are accompanied by the inhibition of motor reactions as well as delayed reactions to stimuli that affect balance, which may increase the risk of falling $[8,9,10]$.

The problem of balance loss becomes more evident with ageing. In individuals aged $50-60$, it is $14 \%$, in septuagenarians $-22 \%$, while in persons aged 80 or older $-33 \%$. In older adults, the majority of falls occur when moving. Most frequently, older adults fall as a result of a forward loss of balance caused by tripping $(60 \%)$. Persons aged 65 or older are 7 times more prone to suffer a fatal fall than young individuals. However, only $5-15 \%$ of falls result in serious head injuries, fractures, sprains or soft tissue damage $[1,11,12]$.

A lot of studies on balance in older adults confirm the hypothesis that balance abilities deteriorate and the risk of falls increases with ageing. WojciechowskaMaszkowska compared the values of stabilogram parameters in persons aged 22 to 86 . The subjects were divided into 3 groups: students, middle-aged persons and older adults. All of them performed tests on a tensometric platform. It was noted that postural stability (mainly in the coronal plane) decreased with ageing. Also, the study revealed considerable differences in the results in the oldest group. The main conclusions of the study are that lower limb asymmetric loading as well as insufficient strength of postural muscles were found in older adults [13]. A similar division of study participants into age groups was implemented by Abrahamova, who sought correlations between age and the centre of pressure (CoP) in 81 individuals aged 20-82. The tests were carried out in eyes-open and eyes-closed conditions on both hard and soft surfaces. The biggest changes in $\mathrm{CoP}$ parameters were noted in older adults, particularly in tests that limited the functioning of somatosensory receptors. A gradual increase in body sways was observed in persons over 60 years of age [4]. Wiszomirska et al. assessed balance in 67 women divided into 3 groups: younger women, older women and women with visual impairments. The tests were performed using AccuSway and Biodex Balance System platforms. As expected, older women were outperformed in dynamic conditions. However, in static tests, their scores were also worse but they were not statistically significant. Under eyes-closed conditions, the best performance was noted in persons with visual impairments. The study pointed to greater sensitivity of dynamic tests compared to static ones [10]. Sieńko et al. investigated postural stability and the risk of falls per decade of adult life. The participants $(n=50)$ aged 20 to 70 were divided into five age sub-groups. The measurements were carried out using the Biodex Balance System platform. As predicted, age of the participants affected their balance and increased the fall risk. The largest differences were found between the youngest and the oldest group. It turned out that the risk of falls increased over 50 years of age. The main conclusion pointed to the earlier occurrence of changes in dynamic balance functions compared to static balance. It may indicate the need to implement preventive exercises at an earlier stage of life [14].

A number of studies have compared balance parameters between young or middle-aged individuals and older adults. The division into more specific age groups is not common. There is also a scarcity of research making use of balance tests under eyes-closed conditions. Thus, the role of vision in controlling postural stability is omitted. This study sought to compare balance and fall risk indexes taking into account the age of the participants.

\section{Material and methods}

The study included female members of the University of the Third Age (U3A) set up at the University of Physical Education in Warsaw who had belonged to U3A for at least two years. This U3A offers a wide variety of physical activity classes. The study was approved by the Ethics Committee of the University of Physical Education in Warsaw (SKE 01-60/2017) and it was completed within statutory activities of the University of Physical Education in Warsaw (no. DS. 292) financed by the Polish Ministry of Science and Higher Education. All the participants gave their written informed consent after being provided with an explanation of the risks and benefits resulting from participating in this study. They had the option to withdraw from the study at any time. Fifty-nine women aged 60 or older 
Tab. 1. Characteristics of the study participants with regard to age ( $x \pm \mathrm{SD})$

\begin{tabular}{lcccc}
\hline Group [age] & $\mathrm{n}$ & Age [yrs] & Body height [cm] & Body mass [kg] \\
\hline $1(60-64)$ & 14 & $63.0 \pm 1.36$ & $160.71 \pm 6.16$ & $64.0 \pm 7.05$ \\
$2(65-69)$ & 19 & $67.4 \pm 1.46$ & $159.74 \pm 4.62$ & $63.8 \pm 6.75$ \\
$3(70-74)$ & 10 & $72.1 \pm 1.45$ & $158.30 \pm 4.97$ & $64.0 \pm 6.87$ \\
$4(75-79)$ & 7 & $75.6 \pm 0.53$ & $156.67 \pm 6.80$ & $64.2 \pm 6.92$ \\
$5(\geq 80)$ & 9 & $82.2 \pm 2.39$ & $156.25 \pm 6.92$ & $64.3 \pm 6.97$ \\
Total & 59 & $70.5 \pm 6.90$ & $158.73 \pm 5.70$ & $63.7 \pm 6.78$ \\
\hline
\end{tabular}

took part in the study. In order to assess their balance performance in age categories, they were divided into 5 groups (Tab. 1).

To exclude any balance disorders, the participants performed static and dynamic tests of Unterberger, Babiński-Weill and Romberg [15]. In all the tests, the results were negative. The women did not report any orthopaedic conditions or pains that would prevent them from taking part in the study. To be able to participate in sports activities organised by U3A, it is necessary to provide a proper medical certificate. During the study, no data concerning any coexisting diseases (arteriosclerosis, diabetes, neurological disorders, etc.) were collected. The Biodex Balance System SD platform with stable and unstable surfaces was used in the study. The platform was connected to the Medical System Biodex Inc. software that made it possible to measure sways in each axis. The overall stability index (OSI), the anteroposterior stability index (APSI), the mediolateral stability index (MLSI) and the fall risk test were used in the analysis. High values of the indexes point to large body sways and poorer balance performance. The following tests were performed on the Biodex platform:

1. Standing on both feet with eyes open on a stable surface

2. Standing on both feet with eyes closed on a stable surface

3. Fall Risk Test [16]

Statistical analysis of the data gathered was performed using STATISTICA (v.13). Kolmogorov-Smirnov test was used to evaluate the data for normal distribution. ANOVA was applied to assess balance performance with regard to age. Non-parametric U Mann-Whitney test was employed to compare the groups in terms of balance performance and the fall risk $(\mathrm{p}<0.05)$.

\section{Results}

Group 5 (over 80 years of age) demonstrated the worst balance performance with eyes open: OSI $0.70 \pm 0.47$; APSI $-0.49 \pm 0.30 ;$ MLSI $-0.37 \pm 0.43$.
The best values of balance performance were manifested by group 2 (65-69 years): OSI $-0.36 \pm 0.13$; APSI $-0.25 \pm 0.08$; MLSI $-0.18 \pm 0.11$ (Fig. 1).

Compared to eyes-open conditions, the tests performed with eyes closed revealed smaller differences between the groups in OSI. The poorest balance performance in APSI was observed in group 4 (APSI: 1.20), whereas the best one was noted in group 1 (APSI: 0.81). When it comes to MLSI, groups 2 and 4 had the same mean scores (MLSI: 0.56), and these results were the best. The worst score in MLSI was achieved by group 3 (MLSI: 0.75) (Fig. 2)

The lowest fall risk was noted in groups 1 (1.89) and 2 (1.87). The highest fall risk was observed in group 4 (3.84) (Fig. 3).

Based on the test results, balance performance differed between individuals from particular age groups. The largest number of statistically significant differences was found when comparing groups 2 and 4 . The differences occurred in OSI under eyes-open conditions, in all balance indexes (OSI, APSI, MLSI) under eyesclosed conditions and in the fall risk index. Statistically significant differences were noted when comparing groups 2 and 5 as well as groups 4 and 5. The comparison between groups 1 and 4 as well as groups 2 and 3 revealed one significant difference in the parameters under examination (Tab. 2).

\section{Discussion}

Numerous studies have revealed that balance performance deteriorates with ageing $[4,10,13,14]$. Due to involutional changes, muscle mass and strength decrease. It stems from a decline in the neuromuscular and skeletal system performance and a reduction in physical activity among older adults [1,10]. A lot of scientists deal with the issues of balance disorders and the fall risk as well as their prevention in older adults [17-20]. These activities aim to prevent the consequences of falls and, as a result, reduce the costs of health care [10]. 


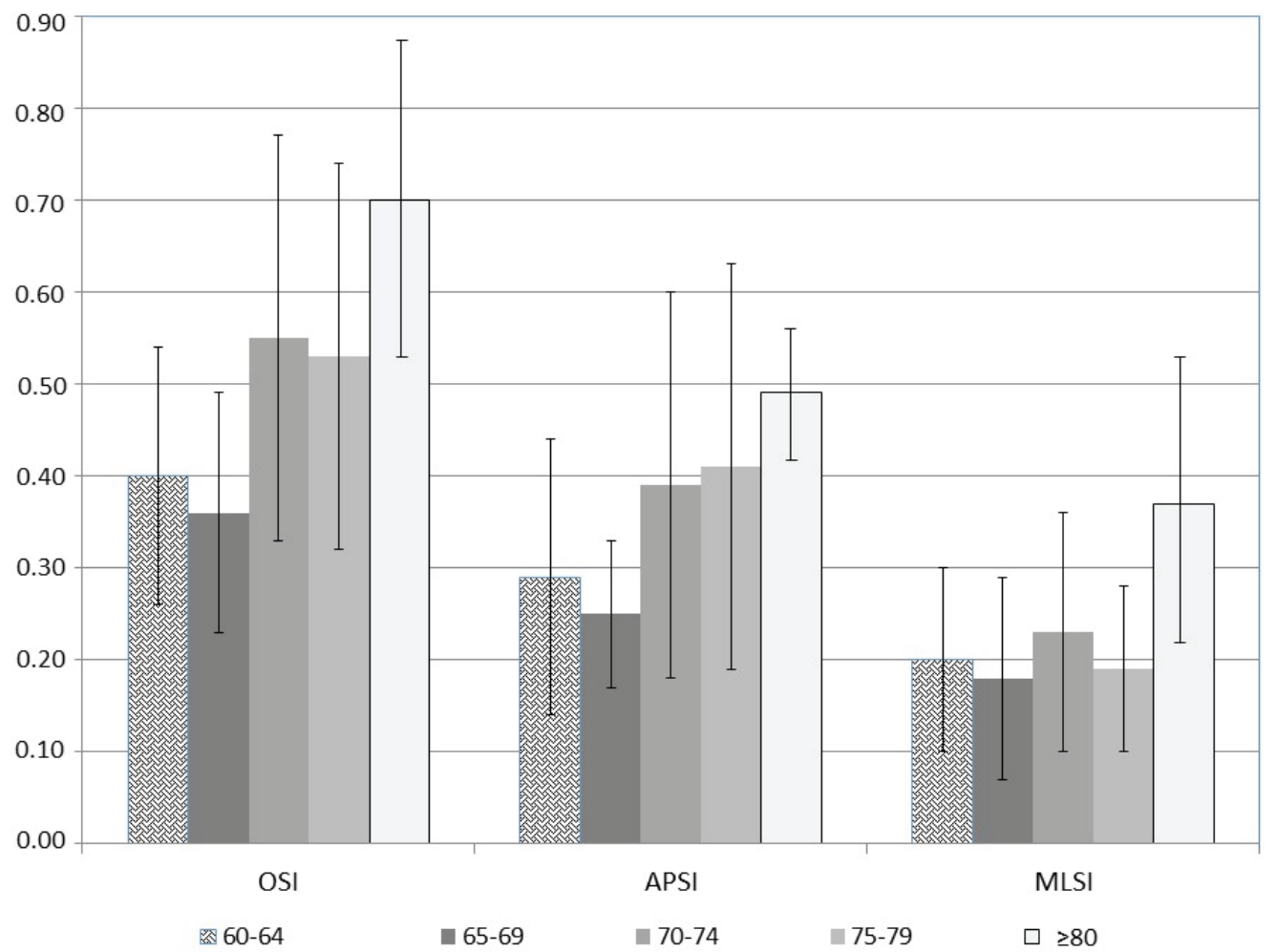

Fig. 1. Balance performance of the study participants under eyes-open conditions with regard to age. OSI - overall stability index, APSI - anteroposterior stability index, MLSI - mediolateral stability index

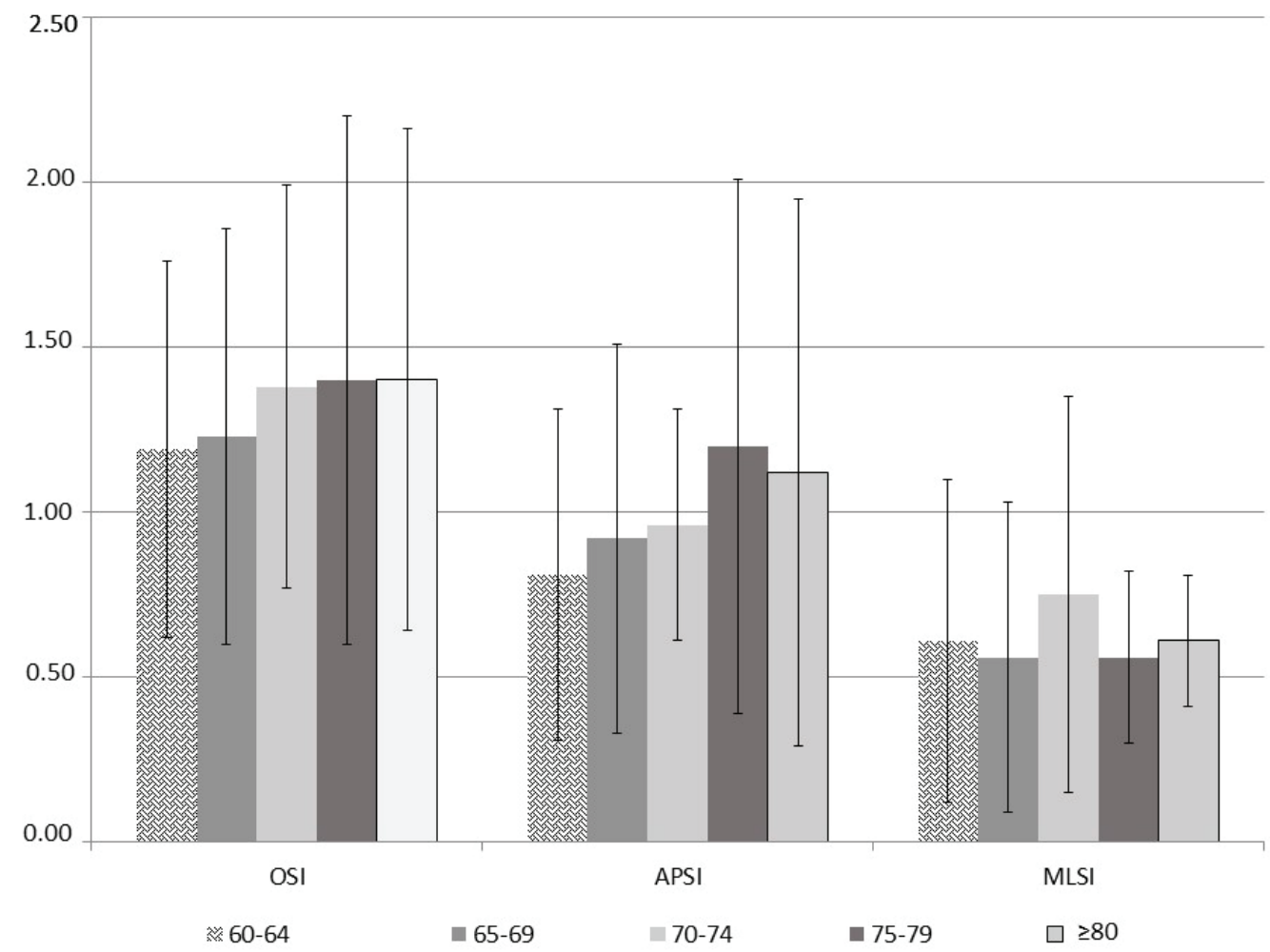

Fig. 2. Balance performance of the study participants under eyes-closed conditions with regard to age. OSI overall stability index, APSI - anteroposterior stability index, MLSI - mediolateral stability index 


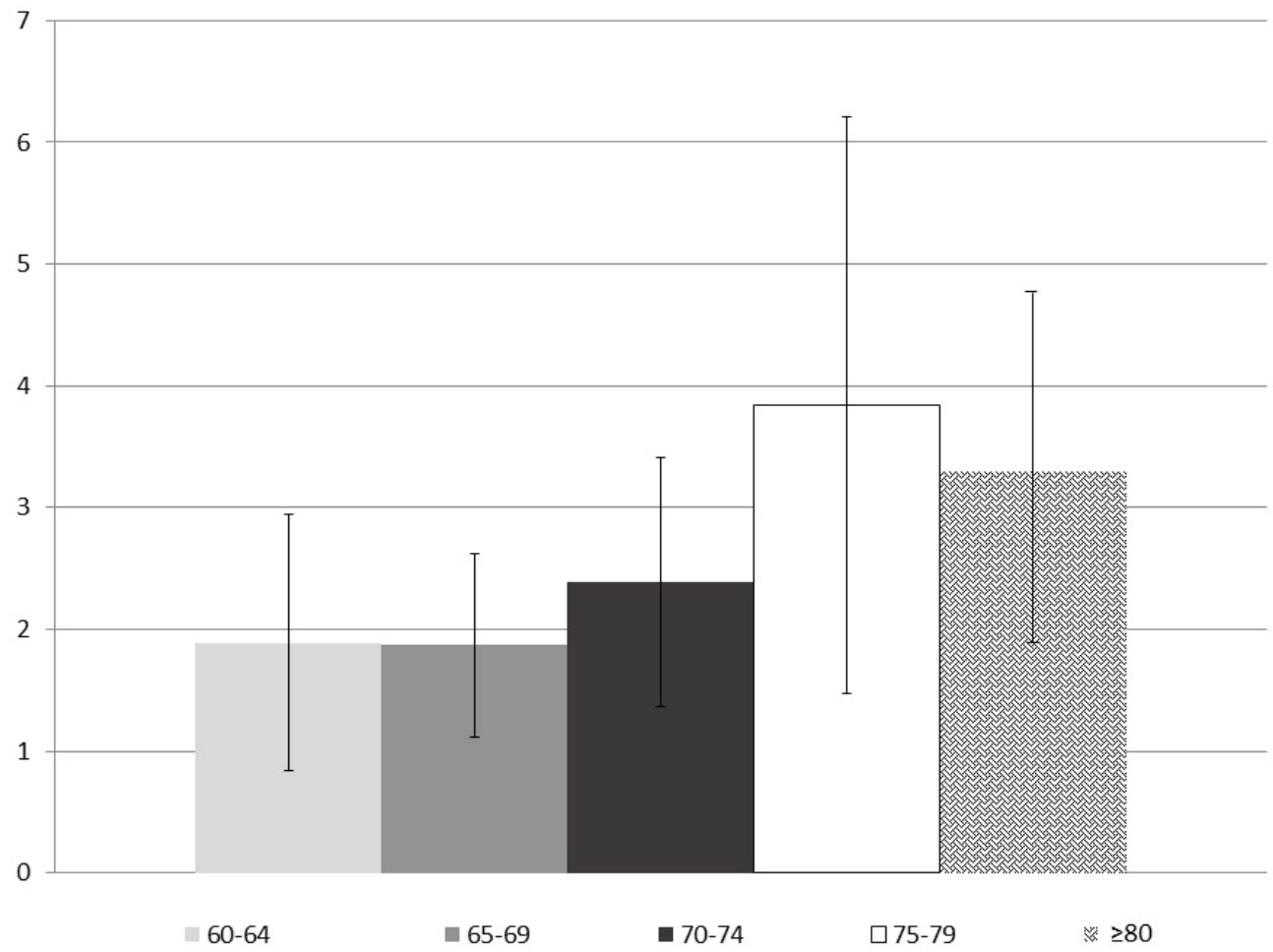

Fig. 3. The fall risk index in the study participants with regard to age

Tab. 2. Comparison of balance and fall risk indexes between age groups

\begin{tabular}{lccccccc}
\hline Age group & OSI EO & APSI EO & MLSI EO & OSI EC & APSI EC & MLSI EC & Fall risk \\
\hline 1vs2 & 1.020 & 0.528 & 0.765 & -0.036 & -0.455 & 0.310 & -0.513 \\
1vs3 & -1.317 & -1.054 & -0.468 & -0.644 & -0.878 & -0.556 & -1.230 \\
1vs4 & -1.044 & -1.194 & 0.150 & -0.970 & -1.156 & -0.373 & $-2.037^{*}$ \\
1vs5 & -1.701 & -1.732 & -1.102 & -1.008 & -0.882 & -0.819 & -0.756 \\
2vs3 & $-2.390^{*}$ & -1.606 & -1.147 & -0.803 & -0.941 & -0.987 & -0.574 \\
2vs4 & $-1.994^{*}$ & -1.792 & -0.376 & $3.815^{*}$ & $-2.197^{*}$ & $-2.428^{*}$ & $-2.050^{*}$ \\
2vs5 & $-2.558^{*}$ & $-2.780^{*}$ & -1.721 & -0.689 & -0.738 & -1.156 & -0.720 \\
3vs4 & 0.049 & -0.244 & 0.586 & 0.439 & -0.098 & 0.146 & -0.812 \\
3vs5 & -0.408 & -0.857 & -0.531 & 0.449 & 0.367 & -0.163 & -0.053 \\
4vs5 & -0.476 & -0.423 & -1.006 & $-3.281^{*}$ & 1.482 & $-2.011^{*}$ & 1.066 \\
\hline
\end{tabular}

${ }^{*} \mathrm{p}<0.05 ; \mathrm{Z}$ value (U Mann-Whitney test) was presented in the table; $1-5$ - age groups, OSI - overall stability index, APSI - anteroposterior stability index, MLSI - mediolateral stability index, EO - test with eyes open, EC - test with eyes closed.

As expected, the findings of the present study showed that the worst balance performance under eyesopen conditions was demonstrated by group 5 , i.e. the oldest group (over 80 years of age). Compared to other groups, the biggest difference occurred in MLSI. A similar correlation was noted by Wojciechowska-Maszkowska, who reported the largest postural instability in the coronal plane in older adults. The researcher attributes it to the development of compensatory mechanisms of lower limb asymmetric loading during free standing, which enables older adults to shorten the time of reaction to balance loss [13]. The review of the literature on balance performance under eyes-open conditions with regard to age indicates that the youngest study participants achieve the best results $[4,13,14]$. In our study, it was group 2 (65-69 years), and not group 1 (60-64 years) that manifested the best balance performance. The lower age limit for female members of U3A at the 
University of Physical Education in Warsaw is 60 years. Participation in physical activity classes may contribute to an improvement in balance parameters. That may be the reason why balance performance was at a higher level in the older and better prepared (owing to their longer experience at U3A) group of the study participants. Full interpretation of the obtained data may be hindered by the lack of information regarding any coexisting diseases (arteriosclerosis, diabetes, neurological disorders, etc.).

The test performed with eyes closed revealed smaller differences between the groups than in the case of the eyes-open tests; however, balance performance under those conditions was poorer. Balance deterioration resulting from the exclusion of vision from the examination has been reported by other researchers $[4,10]$. Lee, who compared balance performance in older adults who had visual impairments of various degrees, revealed that balance disorders deteriorate together with an increase in the level of dysfunction [21]. In the current study, smaller differences in balance performance noted in tests performed under eyes-closed conditions may point to the fact that vision plays an important role in controlling balance in older adults regardless of their age group. It may indicate the need to maintain an optimal level of the function of vision over 60 years of age.

The findings of the present study showed the lowest fall risk in the youngest groups under investigation: 1 (60-64 years) and 2 (65-69 years). Persons from group 4 (75-79 years) proved to be prone to falls the most. Sieńko indicated a similar correlation when assessing changes in the fall risk but in individuals aged 20 to 70 [14]. The results of numerous studies show an increase in the fall of risks with ageing $[10,17,19]$. The fact that the comparison of group 5 (over 80 years of age) and group 4 (75-79 years) in the current study revealed a reduced risk of falling in the former group may point to a critical period for the index under examination, and to a possibility of developing adaptive mechanisms that help to prevent falls in persons aged 80 or older.

Statistical analysis did not reveal any significant differences in the analysed balance indexes between the youngest and the oldest group of the study participants. However, such differences were found in the case of the fall risk index. The comparison between groups 2 and 4 showed the largest number of significant differences. The differences concerned OSI under eyes-open and eyes-closed conditions, APSI and MLSI under eyesclosed conditions as well as the fall risk index. It turned out that the best balance performance was manifested by group 2 , whereas the worst one was demonstrated by group 4 . The findings indicate that balance performance may depend on other factors as well. Sieńko presented the results of research in which middle-aged individuals had better balance than younger persons [14]. A similar situation was observed by Abrahamova [4]. Better balance in younger persons (compared to older ones) was noted by Nolan [22] and Wojciechowska-Maszkowska [13]. It is worth highlighting the fact that the mean value of the fall risk index in the whole group of participants was 2.28. This value is within the norms for persons aged 36 to 53 [16], which points to overall high level of balance in the examined women.

\section{Conclusions}

1. The exclusion of vision in the process of controlling postural stability exerts a negative influence on balance performance. In balance tests with eyes open, the participants achieved much higher scores. It may point to the fact that older adults rely on their vision when keeping balance.

2. Taking part in physical activity classes at U3A located at the University of Physical Education in Warsaw may have had a positive influence on balance performance and may have contributed to a reduction in the risk of falls in the study participants. It may stem from the fact that the mean value of the fall risk index in the whole group of participants was within the norms for persons aged 36 to 53 , which shows that it is possible to improve balance through training even at an older age.

3. Balance performance deteriorates and the fall risk increases with ageing, which is confirmed by a large body of findings compared in particular age groups. It points to the need to implement preventive exercises at an earlier stage of life.

\section{Funding}

The study was completed within statutory activities of the University of Physical Education in Warsaw (no. DS. 292) financed by the Polish Ministry of Science and Higher Education.

\section{Conflicts of interest}

The authors declare no conflict of interest.

\section{References}

1. Błaszczyk JW, Czerwosz L. Stabilność posturalna w procesie starzenia. Gerontol Pol. 2005; 1: 25-36.

2. Fabre JM, Ellis R, Kosma M, Wood RH. Fall Risk Factors and a Compendium of Falls Risk Screening Instruments. J Geriatr Phys Ther. 2010; 30: 184-97.

3. Ołdak K, Ostrowska B, Nowakowska A, Giemza C. Assessment of the risk of falling, physically active 
older women from different residential environment. Gerontol Pol, 2013; 21(3): 75-82.

4. Abrahamova D, Hlavacka F. Age-related changes of human balance during quiet stance. Psychol Res. 2008; 57: 957-64.

5. Wiszomirska I, Kaczmarczyk K, Błażkiewicz M, Wit A. The impact of a vestibular-stimulating exercise regime on postural stability in people with visual impairment. Biomed Res Int. 2015; 2015: 1-8.

6. Behzad K, Ali Y, Farzaneh G, Homayoun A, Azizmorad P. Neuromuscular Training as the basis for developing the level of the static and dynamic balance in selected students of physical fitness team of Kermanshah. Int J Sport Sci Fit. 2014; 4: 20-38.

7. Bednarczuk G, Wiszomirska I, Marszałek J, Rutkowska I, Skowroński W. Poziom równowagi statycznej osób z dysfunkcją narządu wzroku uprawiających dyscypliny sportu oparte na nawykach otwartych i zamkniętych. Polish J Sport Tour. 2017; 24: 8-12.

8. Allison SA, Brooke-Wavell K, Folland J. High and odd impact exercise training improved physical function and fall risk factors in community-dwelling older men. J Musculoskelet Neuronal Interact. 2018; 18(1): 100-7.

9. Bird ML, Pittaway JK, Cuisick I, Rattray M, Ahuja KDK. Age-Related Changes in Physical Fall Risk Factors: Results from a 3 Year Follow-up of Community Dwelling Older Adults in Tasmania, Australia. Int J Environ Res Public Health. 2013; 10: 5989-97.

10. Wiszomirska I, Kaczmarczyk K, Zdrodowska A, Błażkiewicz M, Ilnicka L, Marciniak T. Ocena równowagi statycznej i dynamicznej kobiet młodszych, starszych i z dysfunkcją narządu wzroku. Adv Rehab. 2013; 3 : 33-9.

11. Castro KVB, Candida HLA, Bismarck AS, Furtado AEA., Almeida FJF, Novais TMG et al. Effects of Low Intensity Resistance Training on the Risk of Falls and Functional Autonomy in the Elderly. J Exerc Physiol. 2016; 19(1): 33-8.

12. Edbom-Kolarz A, Marcinkowski J. Upadki osób starszych - przyczyny, następstwa, profilaktyka. Hygeia Public Health. 2011; 46(3): 313-8.
13. Wojciechowska-Maszkowska B. Stabilność postawy ciała u osób w różnym wieku. Akademia Wychowania Fizycznego we Wrocławiu. Praca doktorska. 2007 [Internet] [cited 2020 Jan 12]. Available from: https:// www.dbc.wroc.pl/Content/4306/PDF/Pd_B.W-M_popr.pdf

14. Sieńko-Awierianów E, Lubkowska A, Kolano P, Chudecka M. Postural stability and risk of falls per decade of adult life - a pilot study. Anthropol Rev. 2018; 81: 102-9.

15. Kulma D. Zawroty głowy jako problem orzeczniczy. Orzecznictwo Lekarskie. 2009; 6(2): 135-47.

16. Biodex.com [Internet] [cited 2020 Jan 12]. Available from: https://www.biodex.com/sites/default files/950300man 08060.pdf

17. Cakar E, Dincer U, Kiralp MZ, Cakar DB, Durmus O, Kilac H, et al. Jumping combined exercise programs reduce fall risk and improve balance and life quality of elderly people who live in a long-term care facility. Eur J Phys Rehab Med. 2010; 46: 59-67.

18. Clemson L, Singh MF, Bundy A, Cumming RG, Weissel E, Munro J, et al. Pilot study: a randomized trial of balance and strength training embedded in daily life activity to reduce falls in older adults. Aus Occup Ther J. 2010; 57: 42-50.

19. Gusi N, Adsuar JC, Corzo H, Pozo-Cruz B, Olivares PR, Parraca JA. Balance training reduces fear of falling and improves dynamic balance and isometric strength in institutionalized older people: a randomized trial. J Physiother. 2012; 58: 97-104.

20. Klenk J, Kerse N, Rapp K, Nikolaus T, Becker C, Rothenbacher D, et al. Physical Activity and Different Concepts of Fall Risk Estimation in Older People Results of the ActiFE-Ulm Study, PLOS ONE. 2015; 10(6): 1-11.

21. Lee HK, Scudds RJ. Comparison of balance in older people with and without visual impairment. Age and Ageing. 2001; 6: 643-9.

22. Nolan M, Nitz J, Choy NL, Illing S. Age-related changes in musculoskeletal function, balance and mobility measures in men aged $30-80$ years. The Aging Male. 2010; 13: 194-201. 